The digestive strength of the trypsin and the resistance of the living parameciums having been determined by these control experiments, an attempt was made to lower the resistance of the organisms to tryptic activity by decreasing their oxidative processes. Five c.c. of the activated dialyzed pancreatic juice were exposed to the radiation from a quartz mercury-vapor burner for one hour to destroy the trypsin. Living parameciums were introduced into this inactive juice, and hydrogen gas was bubbled through it for ten hours at $30 \mathrm{C}$. The purpose of bubbling the hydrogen gas through the juice was to deprive the parameciums of most of the oxygen dissolved in the liquid and thus decrease the oxidative processes of the parameciums. At the end of the ten hours the organisms were alive and active. This experiment shows that the hydrogen gas bubbled through the liquid was not injurious to the parameciums and that there remained in the liquid sufficient oxygen for the life processes of the organisms.

Five drops of water containing parameciums were introduced into 5 c.c. of the activated dialyzed pancreatic juice. Hydrogen gas was bubbled through this liquid as it had been through the inactive juice containing the parameciums. The organisms were observed under the microscope at frequent

\title{
DISCISSION AND ADJUSSTMENT OF AN INTRA-UTERINE STEM VER- SUS DILATION
}

TO OVERCOME STENOSIS OF THE CERVICAL CANAL

$$
\begin{aligned}
& \text { H. J. BOLDT, M.D. } \\
& \text { NEW YORK }
\end{aligned}
$$

Next to curetting, dilation of the cervical canal, principally to overcome sterility, is the operation most frequently done without proper indication.

Those who have made observations will probably concede that in 75 per cent. of patients so treated, the intervention is unwarranted, because of absence of narrowing of the cervical canal, acute flexion, or azoospermia in the husband.

Let us take for granted, however, that there is an indication present: the cervical canal narrowed, or an

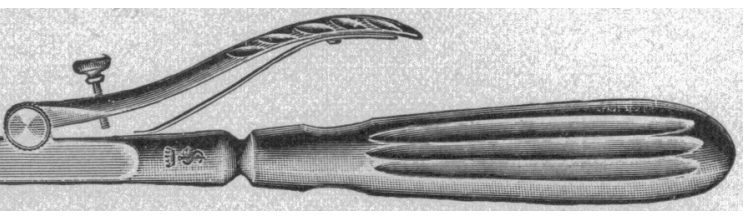

Fig. 1.-Simpson's hysterotome.

intervals during the experiment. After about two hours the animals were observed to move less rapidly than at the beginning of the experiment. A little later these slowly moving organisms became more transparent and moved more slowly. As digestion proceeded, the transparency of the parameciums increased, and at the end of the third hour the partially digested organisms appeared as shadows. About half an hour later these parameciums had been completely digested and had gone into solution. These organisms were literally digested while alive and killed by the action of the trypsin itself in the process of digestion.

The preceding experiment was repeated, and when the animals were partially digested, the bubbling of hydrogen gas through the liquid was discontinued and the bubbling of oxygen gas was substituted. 'When this was' done, the organisms that had not been too much digested were revived, and lived on as normal animals.

These experiments show that the resistance of these unicellular organisms to the digestive action of trypsin is greatly reduced when their oxidative processes are decreased, and that their resistance returns when the oxidative processes are restored. The results obtained on these living unicellular organisms would appear to lend support to the hypothesis advanced in explaining the resistance of the living cells of the gastric mucosa to the digestive action of pepsin.

\section{CONCLUSIONS}

The decreased resistance of a circumscribed area of the stomach to the digestive action of gastric juice is due to a decrease in the oxidative processes of the cells of the area. Gastric ulcer is due to the subsequent digestion of the area by pepsin.

The resistance of unicellular organisms (parameciums) to the digestive action of the proteolytic enzymes can be increased or decreased by increasing or decreasing the intensity of the oxidative processes of the organisms, the greater the intensity of the oxidative processes the greater the resistance, and vice versa.

The Soul of Enjoyment.-Health is the soul that animates all enjoyments of life, which fade and are tasteless, if not dead, without it.-Sir William Temple. acute flexion. Is cervical dilation, then, really the best means of giving pcrmanent relief?

Judging from my personal experience, the question must be answered negatively, since it will be found in many cases that within from two to four months the cervical canal has again become constricted. There is, however, a method of intervention which will positively obviate this.

Cervical discission with adjustment of an intrauterine stem will give such guarantee.

With the patient in the lithotomy position, the cervix, having been exposed with vaginal retractors, is drawn down and steadied with bullet forceps. Then with a Simpson hysterotome (Fig. 1) set with the thumbscrew before it is introduced, in order that the depth of the discission may be gaged, the cutting blade being held firmly at the chosen part, the handle is firmly depressed and the instrument withdrawn slowly. The cervical canal should not be dilated before the operation, lest it confuse the operator as to the extent of the discission advisable.

I prefer to make the discission on the anterior and posterior surfaces of the interior of the cervix, since there is no danger of cutting vessels there, whereas on one occasion I had a profuse and serious hemorrhage by cutting laterally.

When the discission has been made, an intra-uterine stem (Fig. 2) of suitable size is adjusted. I have these stems made in various sizes. They are of hard rubber.

The lower part, through which the retaining suture of very heavy silkworm gut is passed, is solid; but the upper part is hollow, making it as light as possible, and preventing the weight of the stem, by bearing on the suture, cutting downward, which is frequently the case with the heavier glass stems used by Baldwin. I have found also the solid rubber stems too heavy for my. purpose, that of leaving the stem in situ for about six weeks.

The suture is fastened by shot, beneath which a small lead plate is placed to prevent the shot from 
burying itself in the cervical tissue. It is easily removed at the desired time, and one may be sure that the cervical canal will then not again contract as in a simple dilation.

The stems, for purposes of sterilization, are kept in compound solution of cresol or a saturated phenol (carbolic acid) solution.

39 East Sixty-First Street.

\section{BULLET LESION OF CAUDA EQUINA}

\section{G. B. HASSIN, M.D.}

Attending Neurologist, Cook County Hospital

K. L. JOHNSTONE, M.D.

A. M. CARR, M.D.

CHICAGO

While bullet lesions of the cauda equina might be of frequent occurrence in time of war, they are unusually rare in time of peace. Thus Braun ${ }^{1}$ saw but one case in twenty-five years in one of the large Berlin hospitals, and Chipault ${ }^{2}$ says that both vertebral and spinal cord gunshot lesions are very rare, not only. in every day practice, but even in time of war.

The literature, therefore, on gunshot wounds of the cauda equina, to be reported below, is very scarce indeed. Serious as these lesions have been in the majority of cases, their prognosis has been and is much more favorable than similar spinal cord lesions, notwithstanding the length of time in which the bullet might be lodged within the cauda.

In the present case, it remained there for six years, when it was finally removed with remarkable improvement in the subjective and objective conditions of the patient.

\section{REPORT OF CASE}

History-Man, aged 28, entered Cook County Hospital, Sept. 2, 1915, complaining of pain in the left lower extremity. The pain would "jump" from the left buttock to the left popliteal region, whence it would reach the left little toe and spread all over the foot and the rest of the toes. It would stop for about five or ten minutes, and then start again. The patient had to take morphin, sometimes as much as 30 grains daily; he drank beer, whisky, even wood alcohol, in fact, anything he could get hold of, to stop the unbearable pain. He could not sleep nights, could not find rest in the daytime, and could not do his work (that of a watchman), but was able to walk.

1. Braun, W., and Lewandowsky, M.: Beiträge zur Frage der operativen Behandlung der Rückenmarksschüsse, Deutsch. Ztschr. $\dot{\text { f. }}$ Chir., 1908, xl, 115

2. Chipault, in Le Dentu and Delbet: Traité de chirurgie clinique et opératoire, Paris, 1897, iv, 881 .

The pain originated six years ago after he had been shot in the back. One attempt to remove the bullet, four hours after he was shot, was entirely unsuccessful. The patient applied afterward about five times to the Cook County Hospital with a request to have the bullet removed, but each time operation was refused, the last time about three years ago.

In addition to the pain the patient felt weakness, especially in the left foot, which started to "give way" about ten months ago, and lately the weakness became so great that he was afraid to walk on a slippery day. He had to be careful in walking, as the right toes would "kick" the ground, and cause frequent damage to his shoes. To avoid kicking the ground he had to raise the right foot higher, while the left foot would turn inward. He was lame, as the body weight was thrown toward the left. Following the shooting, the patient immediately became paralyzed in both lower extremities. The paralysis was combined with anesthesia and loss of sphincter control. A month later cystitis developed which persisted for two years, during which time there also was loss of sexual power, though erections and desire were present. He could not move around for two years, and had to be "carried all this time in a rocker." Aside from the shooting accident, there was nothing of importance in the patient's previous history. Venereal diseases were denied; his wife had had no miscarriages; there were two healthy children.

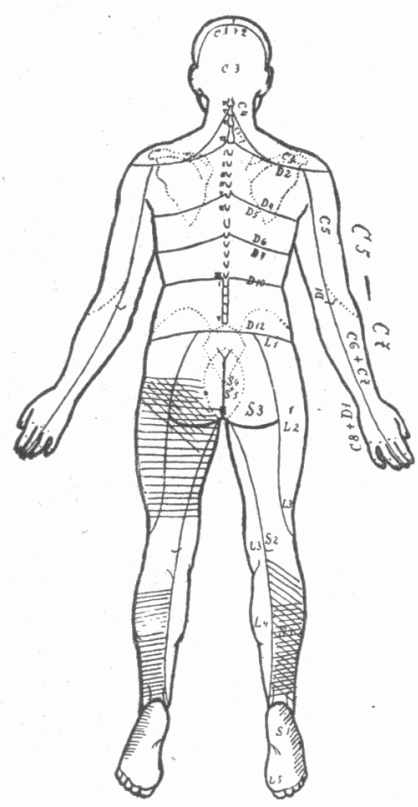

Examination. - This revealed a well nourished white man with normal cranial nerves, normal heart, normal mentality and normal condition of the genito-urinary organs.

The right thigh and the left leg showed muscular atrophy with a clawlike position of the left toes. Measurements of the thighs, 12 inches above the external condyle. gave 18 inches for the right, and 19 for the left; the calf muscles, 12 inches above the malleoli, gave $121 / 4$ for the right, and $111 / 4$ for the left. The muscle power in the extensors and abductors of the left leg was much stronger than on the right, while the left leg muscles (the gastrocnemius) were somewhat weaker than the right ones.

The tendon reflexes, patellar and the Achilles tendon, were absent on the left, and on the right side only the patellar was present. The sensibility was merely reduced, for pain, touch and temperature in the areas supplied principally by the last two lumbar and first two sacral roots (Fig. 1). The electric examination showed complete reaction of degeneration in the left posterior tibial and left gastrocnemius, and a partial reaction of degeneration in the right extensors of the leg. Besides motor, sensory and electric changes, there were also present vasomotor and trophic disturbances. The former were represented by excessive sweating of the left foot, the latter (trophic) by the atrophies and several scars from burns caused by leaning against a radiator, the heat of which was not felt by the patient.

A combination of such findings suggested a scattered peripheral lesion of some of the nerves and muscles of the lower limbs which resulted in a peculiar clinical picture: atrophy of the right thigh, of the left leg, of the small muscles of the left foot, combined with severe pain in the left leg and motor weakness in the right leg. In addition, there were present localized electric and vasomotor changes coupled with bilateral loss of Achilles and unilateral loss of (right) patellar reflexes. Such a scattered combination of atrophies did not 